\title{
Repensando a motivação metonímica da metáfora: uma análise pela perspectiva da Integração Conceitual
}

\author{
Rethinking metonymic motivation of metaphor: an analysis by the perspective \\ of conceptual integration
}

\section{Natália Elvira Sperandio}

Universidade Federal de Minas Gerais - UFMG - Pampulha - Belo Horizonte - Brasil

\begin{abstract}
Resumo: estudos contemporâneos postulam a possibilidade de interação entre os processos metafóricos e metonímicos na produção de sentido. Autores como Goossens (2003), Barcelona (2003) e Radden (2003) redimensionaram seus esforços em busca de modelos que pudessem comprovar a ocorrência dessa interação. No entanto, as pesquisas desenvolvidas por esses autores consideram apenas a possibilidade da existência do processo metonímico, atuante na motivação do processo metafórico, ou no domínio-fonte, ou no domínio-alvo da metáfora motivada. Diante disso, este artigo, como parte de uma pesquisa mais ampla de doutorado, tem a finalidade de demonstrar a possibilidade da metáfora ser motivada por um conjunto complexo de metonímias, sendo esse conjunto presente tanto em seu domínio-fonte quanto em seu domínio-alvo. Para nossa análise, utilizaremos a Teoria da Integração Conceitual em conjunto com trabalhos dedicados ao estudo dos processos metafóricos e metonímicos.
\end{abstract}

Palavras-chave: Metáfora. Metodologia. Interpretativismo, Dialogismo. Pensar Alto em Grupo.

Abstract: contemporary studies postulate the possibility of interaction between the metaphorical and metonymic processes in the production of meaning. Authors like Goossens (2003), Barcelona (2003) and Radden (2003) re-dimensioned their search efforts models that could prove the occurrence of this interaction. However, research carried out by these authors, only consider the possibility that the metonymic process, active in the motivation of the metaphorical process, or in the field source or target area of motivated metaphor. Therefore, this article as part of a broader research doctorate, is intended to demonstrate that metaphor is motivated by a complex set of metonymy, and that set this either in your source domain and in your target area. For our analysis, we will use the theory of conceptual integration in conjunction with works devoted to the study of metaphorical and metonymic processes.

Keywords: Metaphor. Metonymy. Metaphorical/metonymic interaction. 


\section{Introdução}

Estudos contemporâneos em Linguística Cognitiva postulam a possibilidade de interação entre os processos metafóricos e metonímicos na produção de sentido. Como exemplo temos as pesquisas propostas por Goossens (2003), Barcelona (2003) e Radden (2003) que sistematizam a interação conceitual desses processos. Esses autores redimensionaram seus esforços em busca de modelos que pudessem comprovar a ocorrência dessa interação. No entanto, os trabalhos propostos por esses pesquisadores demonstram a ocorrência da motivação metonímica da metáfora apenas em um de seus domínios. Isto é, de acordo com essas pesquisas, haverá a possibilidade do processo metonímico, responsável pela motivação da metáfora, ocorrer ou no domínio-fonte, ou no domínio-alvo da metáfora motivada. '

Diante disso, esta pesquisa, como parte de um projeto maior de doutorado, possui a proposta de averiguar a possibilidade de ocorrência da motivação metonímica em ambos os domínios da metáfora. Ou seja, nossa finalidade consiste em evidenciar a presença da motivação metonímica tanto no domíniofonte quanto no domínio-alvo da metáfora motivada.

Para o desenvolvimento de nossa proposta de estudo, recorreremos aos trabalhos sobre interação metafórica/metonímica propostos por Goossens (2003), Radden (2003) e Barcelona (2003). O conceito de metáfora utilizado é o desenvolvido por Lakoff e Johnson (1980), na Teoria da Metáfora Conceitual, pois esse propõe uma análise mais ampliada do processo metafórico, considerando-o não como uma figura de linguagem, mas como fenômeno cognitivo presente em nossas conceitualizações.

O processo metonímico será conceitualizado a partir dos trabalhos de Radden e Kövecses (1999). Além disso, buscaremos subsídios nas pesquisas de Jakobson (2003) e Paiva $(2010,2011,2012)$ por meio das propriedades contígua, recursiva e fractalizada. Com essa articulação, temos a possibilidade de promover um estudo mais abrangente do modelo metonímico.

Como forma de evidenciarmos esse processo interativo, recorreremos à Teoria da Integração Conceitual desenvolvida por Fauconnier e Turner (2002). A escolha por essa perspectiva teórica decorre do fato de ela não considerar apenas metáforas cristalizadas, isto é, aquelas metáfora que encontramos em nosso cotidiano, mas também as denominadas metáforas criativas. Além disso, por meio da integração conceitual, vislumbramos a ocorrência de um mapeamento múltiplo, ou seja, de ambos os domínios, fonte e alvo, na criação do espaço mescla, local em que ocorrerá a produção do modelo metafórico.

O objeto de estudo nomeado para esse artigo é a charge animada, em específico a charge intitulada "O ogro e o burro". Essa charge foi produzida por Maurício Ricardo e pode ser acessada em seu site charges.com.br. A escolha desse objeto decorre do fato de abordar de forma condensada e bemhumorada assuntos diários, com críticas que expressam opinião. E com o advento da tecnologia a charge adquiriu novos formatos, possibilitando a introdução de novos elementos em sua composição, como cores, animação e som. Com esses elementos temos a possibilidade de acrescentar e produzir diferentes ângulos de exposição dos fatos e interpretação através, por exemplo, da voz de um personagem, ou seja, a partir de todos os recursos tecnológicos disponíveis. Elementos esses que podem contribuir para a nossa pesquisa, pois teremos outros modos, além do verbal, atuando na criação das metáforas e metonímias analisadas.

Nosso artigo será dividido em duas partes, sendo a primeira teórica. Nessa seção apresentaremos, de forma sucinta, as teorias escolhidas para o nosso trabalho. Na segunda parte, analítica, aplicaremos as teorias eleitas ao nosso objeto de estudo. Nessa seção, evidenciaremos que as metáforas analisadas resultaram de um conjunto complexo de relações metonímicas, sendo essas relações criadas não apenas em um dos domínios dessa metáfora, mas em seus domínios fonte e alvo. 


\section{Metáfora e Metonímia}

Alvo de diversas pesquisas, a metáfora consagrou-se como importante figura de pensamento. Com os estudos promovidos por Lakoff e Johnson (1980), esse fenômeno tornou-se amplamente discutido em diversas áreas, indo além dos limites da linguística. Conceitualizada como a nomeação de uma coisa em termos de outra, essa figura passa a ser vista como fenômeno cognitivo, presente em nosso sistema conceitual e estruturante de nossa forma de pensar, falar e agir. Os autores afirmam que nossa compreensão de mundo está vinculada à concepção da metáfora, já que grande parte dos conceitos que regem nossas vidas é compreendido metaforicamente. Neste trabalho, fazemos uso da Teoria da Metáfora Conceitual pelo fato de ela propor uma análise mais ampliada do processo metafórico, considerando-o não como uma figura de linguagem, mas como fenômeno cognitivo presente em nossas conceitualizações.

O processo metonímico, da mesma forma que o metafórico, tem sua origem entrelaçada aos estudos aristotélicos. Nesse contexto, a metonímia foi conceitualizada como a substituição de uma palavra por outra, às quais estão associadas. Nessa visão tradicional tal figura tinha como característica primária a referencialidade, pois acreditava-se que a substituição por ela estabelecida consistia em uma mera representação de uma coisa por outra, sem que houvesse introdução de um novo significado. Porém, essa visão foi abandonada em favor de uma abordagem conceitual da metonímia como processo cognitivo.

É nessa fase, pautada nos trabalhos cognitivos, que esta pesquisa filia-se. Com esses trabalhos, a metonímia passa a ser vista como importante processo presente em nosso pensamento e agir cotidianos. Com esse intuito, elegemos para nosso trabalho o conceito metonímico apresentado por Radden e Kövecses (1999), descrito como entidade conceitual, veículo, que promove acesso mental a outra entidade conceitual, alvo, em um mesmo modelo cognitivo idealizado.
Além disso, passamos a analisar esse processo como contíguo, tendo como base o trabalho de Jakobson (2003). Para o autor, a propriedade de contiguidade está presente na formação desse processo, colando as entidades que compõem o processo metonímico próximas.

Finalizamos a análise desse processo com base nos trabalhos de Paiva $(2010,2011,2012)$. Para a pesquisadora, da mesma forma que ocorre em um sistema complexo, as entidades de um modelo metonímico possuem organização recursiva. Com isso, por exemplo, a PARTE pode ser projetada sobre o TODO, como esse sobre a PARTE, como também PARTE ou TODO podem ser projetados a outro domínio. Paiva (2010) afirma que por meio dessa operação um aspecto pode ser projetado ao TODO de um mesmo domínio ou integrar outro domínio, permitindo a conceitualização de outra coisa, ou seja, a metaforização. Por outro lado, ela postula também a propriedade fractalizada ao fazer com que, em um modelo metonímico, a mesma coisa seja vista em escalas diferentes. De acordo com a pesquisadora, a propriedade fractal funciona como hiperlink para uma cena maior, como se, por exemplo, um sintagma ou uma imagem representassem um ponto em uma cena com a capacidade de gerar toda a cena. Para a autora, a característica da similaridade dos fractais faz com que a mudança no tamanho da cena e do número de elementos, isto é, mudança de escala não altere o sentido.

\section{A perspectiva da interação metafórica e metonímica}

Goossens (2003) foi o primeiro autor a sistematizar, de forma precisa, a interação entre os processos metafórico e metonímico. O autor encontrou evidências dessa interação que passou a ser denominada, a partir de um neologismo, como metafonímia. De acordo com ele é necessário considerarmos, neste contexto, a questão dos domínios. Em seu trabalho parte-se do pressuposto da existência de domínios complexos construídos pela combinação de outros domínios, sendo esses complexos ou básicos. Nesse sentido as fronteiras 
entre os domínios conceituais são consideradas fluidas, motivo pelo qual pode haver a interpenetração entre metáfora e metonímia. Como forma de explorar essa interação, o autor utiliza como corpus expressões estereotipadas que possuem como domínio-alvo a ação linguística, tendo como domínios doadores partes do corpo, som e ação violenta.

Goossens (2003) inicia seus estudos pela interação cumulativa da metáfora a partir da metonímia. O autor afirma que esse tipo de interação pode ser explicado pelo fato de que "subjacente à metáfora, há o entendimento de que os domínios fonte e alvo podem ser unidos de forma natural e simultânea numa única cena complexa, situação típica da formação da metonímia" (GOOSSENS, 2003, p. 366).

Em relação à interação cumulativa da metonímia à metáfora, o autor argumenta que é mais difícil de ser concebida e possui ocorrência rara, tanto é que ele não a insere em suas análises. No entanto, não nega sua existência. Como forma de exemplificar este tipo de interação ele constrói o seguinte enunciado "Tocar seu próprio trompete" (blow one's own trumpet), pensando em uma situação em que alguém estivesse falando bem de si mesmo. De acordo com ele, a interpretação metafórica é assegurada se mapearmos o caráter festivo ao autoelogio. Goossens (2003), a partir da sentença "Notável, o sujeito está tocando seu próprio trompete" (Remakable, the chap is blowing his own trumpet!), simula a possibilidade dos dois termos ocorrerem juntos.

O segundo tipo de interação, trabalhada pelo autor, a metafonímia integrada, pode ocorrer com uma metonímia dentro da metáfora e da metáfora dentro da metonímia. Para o autor, no primeiro caso, encontrado apenas nos dados envolvendo partes do corpo, temos a criação de metáforas com uma metonímia embutida.

Ruiz de Mendonza e Pérez (2003) postulam que as interações desenvolvidas por Goossens (2003) exemplificam apenas um tipo de modelo interacional, considerado por esses autores como desenvolvimento metonímico da fonte metafórica.
Porém, os pesquisadores afirmam que há possibilidade do processo metonímico ocorrer no domínio-alvo da metáfora. Para exemplificar essa afirmação recorrem ao enunciado "ganhar o coração de alguém". Os autores advogam que os elementos vencedor e prêmio estão presentes no domínio-fonte, enquanto que o domínio-alvo é composto por um amante que deseja, figurativamente, ganhar 0 coração de alguém. O coração, como contêiner de sentimentos, é escolhido para representar o sentimento de amar. Como coração e amor estão em uma relação de domínio-subdomínio haverá o destacamento metonímico de uma parte relevante do alvo metafórico. Como vencer requer esforço e tática, uma implicação conduzida ao domínio-alvo dessa metáfora sugere que a ação de ganhar o coração de alguém é uma tarefa difícil.

Outro estudioso dedicado ao estudo da interação metafórica/metonímica é Barcelona. Seguindo a proposta de Goossens (2003), Barcelona (2003) propõe a existência de dois tipos principais de interação: uma ocorrendo exclusivamente no nível conceitual e outra puramente textual, sendo esta denominada de coinstanciação textual de metáfora e metonímia em uma mesma expressão linguística. A interação no nível conceitual possui dois tipos: motivação conceitual metonímica da metáfora e motivação conceitual metafórica da metonímia.

O autor inicia seus estudos com a motivação conceitual metonímica da metáfora, sendo que, de acordo com ele, essa motivação pode ser vista como problemática, um desafio para a teoria da metáfora, pois um grande número de metáforas passa a ser visto como tendo base metonímica. Como ilustração temos a metáfora IRA É O CALOR DE UM FLUIDO, metáfora investigada por Lakoff e Kövecses (1987) e retomada por Lakoff (1987). Essa metáfora licencia expressões como "Eu tinha atingido o ponto de ebulição" e "Quando falei com ele, ele quase explodiu". Com base nos estudos desses autores, Barcelona (2003) propõe que "essa metáfora é motivada por um grupo de metonímias sobre as quais certos efeitos fisiológicos da ira representam essa emoção" (BARCELONA, 2003, p. 242). 
$\mathrm{Na}$ interação resultante da motivação conceitual metafórica de algumas metonímias é possível apenas em "interpretações metonímicas de uma expressão linguística que são possíveis apenas com a coocorrência do mapeamento metafórico" (BARCELONA, 2003, p. 244). Na ilustração dessa interação, o autor toma emprestada a sentença estudada por Goossens (2003): "Ela tomou o ouvido do ministro e o persuadiu a aceitar seu plano" (She caught the Minister's ear and persuaded him to accept her plan). Nessa sentença temos a metáfora ATENÇÃO É UMA ENTIDADE FÍSICA EM MOVIMENTO e a versão específica da metonímia convencional PARTE DO CORPO POR FUNÇÃO, neste caso OUVIDO POR ATENÇÃO. Tomando a explicação de Goossens (2003), o autor propõe que OUVIDO POR ATENÇÃO coloca-se no mapeamento metafórico, sendo atenção o domínio-alvo, ou seja, apenas quando a atenção torna-se domínio-alvo, desenvolve-se o mapeamento metonímico com orelha representando um atributo específico (atenção) de sua função típica (audição). Assim, essa metonímia específica é encontrada apenas em expressões linguísticas de metáforas conceituais como ATENÇÃO É UMA ENTIDADE FÍSICA EM MOVIMENTO, em que atenção é o domínio-alvo.

Os conceitos de metáfora e metonímia são abordados por Radden (2003) a partir da ideia de continuum, o autor assume a existência de casos difusos entre estas categorias. Em seu trabalho, o pesquisador aborda as noções de literal, metonímia e metáfora como localizados em um continuum, sendo esse já abordado por Taylor (2003). Na tabela a seguir há esta formulação a partir dos diferentes usos do adjetivo alto, com sua transição gradual do literal, passando pela metonímia até a metáfora.

\begin{tabular}{|c|c|c|c|c|}
\hline Literal & & Metonímico & & Metafórico \\
\hline (a) & (b) & (c) & (d) & $(\mathrm{e})$ \\
torre & maré & temperatura & preços & qualidade \\
alta & alta & alta & altos & alta \\
\hline
\end{tabular}

Figura 1 - Tabela continuum literal-metonímia-metáfora (Fonte: Radden (2003, p. 409)).
O autor explica a tabela acima da seguinte forma: em (a) alto é usado literalmente, referindo-se apenas à verticalidade. Em (b) alto é parcialmente, ou fracamente, metonímico fazendo referência tanto à extensão vertical e horizontal, fato que ocorre com a metonímia ACIMA POR ACIMA E MAIS. Em (c) alto é totalmente metonímico, substituindo uma entidade em um mesmo domínio conceitual, a escala de verticalidade representando o grau da temperatura, como em ACIMA POR MAIS. Em (d) alto fica entre a interpretação metafórica e metonímica, pois algumas pessoas fazem a associação de preço alto ou preço em ascensão com uma linha em ascensão em um gráfico, como aqueles utilizados nas bolsas de valores. Por último, alto em (e) refere-se a uma escala de avaliação, a extremidade mais alta do que é bom, sendo que avaliação e verticalidade não podem ser pensadas como parte de um mesmo domínio conceitual, visto como puramente metafórico como BOM É PARA CIMA.

\section{Teoria da Integração Conceitual}

As pesquisas sobre interação metafórica/metonímica apresentadas evidenciam a possibilidade de motivação metonímica da metáfora em apenas um dos domínios dessa metáfora. Como nossa proposta consiste em demonstrar que essa motivação metonímica pode ocorrer em ambos os domínios recorreremos à Teoria da Integração Conceitual (TIC) em nossas análises.

Fauconnier e Turner (2002) postulam que a TIC possui como alvo o estudo de estruturas cognitivas emergentes encontradas em metáforas criativas. Em The way we think os autores enfocam o que acontece nos bastidores da cognição, ou seja, na mente humana durante o processamento cognitivo. De acordo com esses autores, o cérebro funciona a partir de intensas ativações cerebrais das quais resultam construções mentais complexas que ocorrem à medida que pensamos, falamos, agimos e lemos.

Os autores consideram a integração (mescla) conceitual como operação mental básica altamente 
imaginativa, que resulta de uma rede de espaços mentais, com a configuração mínima envolvendo a projeção seletiva de elementos de quatro espaços:

Espaços de input: constituem duas, ou mais estruturas parciais, que correspondem a um conceito, ou traços de conceitos, entendidos como informação prévia relacionadas a experiências definidas.

Mapeamentos: mapeiam, através de conexões parciais, contrapartes dos espaços input.

Espaços genéricos: são espaços mentais que mapeiam o que cada input possui em comum.

Espaço mescla: um novo espaço, onde os elementos dos espaços inputs são projetados.

Estrutura emergente: o espaço mescla, que é resultado da projeção seletiva, apresenta uma estrutura emergente, com uma configuração distinta da apresentada pelos inputs.

Fauconnier e Turner (1999, 2002), ao abordarem o modelo sobre os fenômenos da mesclagem, incluem os papéis dos processos metafóricos e metonímicos na geração de novas estruturas no espaço da mesclagem. Os autores postulam que um dos princípios otimizadores da mesclagem é a compressão metonímica, que torna possível 0 estabelecimento de contrapartes metafóricas. O que isso nos evidencia é que, apesar de não aprofundarem na questão da interação metafórica/metonímica, podemos considerar um encaminhamento para uma maneira de estabelecer a relação entre esses processos. Como forma de compreendermos melhor a abordagem feita pelos autores, sobre o modo em que metáfora e metonímia podem interagir, recorremos à análise proposta por eles do "Ceifeiro Implacável". Nesta mesclagem temos elementos que não são contrapartes em um mesmo espaço: morte, esqueleto de uma pessoa morta e o capuz de um padre. A seguir temos a imagem do ceifeiro como representação da morte:

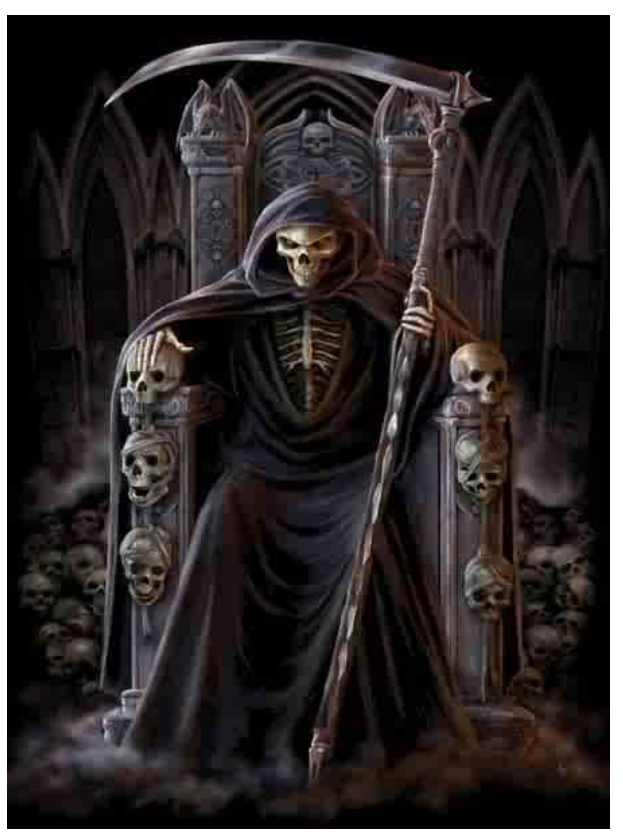

Figura 2 - Ceifeiro Implacável como representação da morte (Fonte:

http://exorcizamusdemon.blogspot.com.br/2010/09/ceifeiros.htm l. Acesso em: 23 fev. 2013).

Essa imagem resulta de quatro espaços: 1) de uma pessoa morrendo, 2) de um padrão abstrato em que um evento é causado por um elemento abstrato, a partir de uma relação de tautologia (morte faz com que alguém morra), 3) um assassino prototípico e 4) o ceifeiro.

A compactação metonímica atua na imagem de diversas formas. Um exemplo é a imagem do esqueleto representando a morte, pois, como os autores colocam, o ceifeiro e o esqueleto não podem ser vistos como contrapartes no mapeamento entre as entradas, mas a morte associa-se metonimicamente ao esqueleto, sendo um de seus efeitos.

Também é possível a associação metonímica, no espaço da pessoa morrendo, da pessoa morrendo com o padre, já que este está presente nos funerais, dando, por exemplo, a unção aos enfermos. Mesmo o padre e o ceifeiro não sendo contrapartes, o ceifeiro aparece na imagem vestindo o capuz. Neste caso, temos a metonímia PARTE pelo TODO, com a vestimenta no lugar do padre. O capuz, por sua vez, associa-se ao desconhecido.

O que a análise nos mostra é que a imagem acima, como metáfora da morte, é construída a partir da integração complexa entre os elementos 
metonímicos apresentados: esqueleto como efeito da morte, a vestimenta no lugar do padre e o rosto encoberto representando o desconhecido. Portanto, podemos considerar que, diferente das pesquisas desenvolvidas por Goossens (2003), Barcelona (2003) e Radden (2003), em que o processo metonímico está presente apenas no domínio-fonte da metáfora, na análise do ceifeiro implacável temos em cada uma das entradas dessa metáfora relações metonímicas, sendo essas as responsáveis pela criação da metáfora da morte.

$\mathrm{Na}$ análise da imagem do ceifeiro, os autores nos demonstram como as relações metonímicas, presentes nos espaços de inputs, atuam na construção da metáfora da morte e, como na mescla, a partir do princípio da restrição metonímica, somos capazes de fazer a aproximação de elementos que não são vistos como contrapartes nos espaços de entrada.

\section{Análise - Charge o Ogro e o burro}

A charge a ser analisada foi produzida no ano de 2010, especificamente no mês de julho. A charge "O ogro e o burro" tem como foco o futebol, em especial a copa de 2010 e a derrota da seleção brasileira.
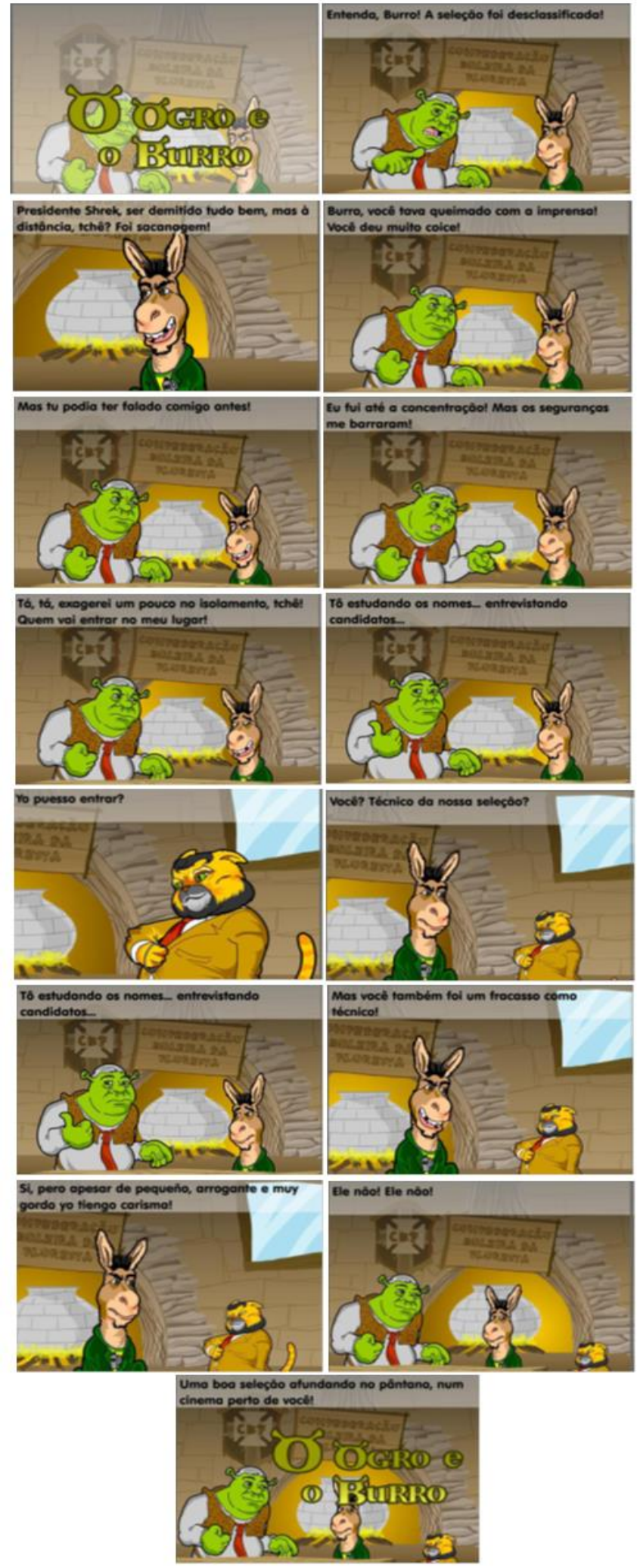

Figura 3 - Charge $O$ Ogro e o Burro (Fonte: http://charges.uol.com.br/2010/07/12/desenhos-o-ogro-e-oburro/. Acesso: 05 out. 2013). 
A charge escolhida é produzida a partir de dois domínios conceituais diferentes: o domínio do futebol e o domínio da história de Shrek. Essa charge possui em sua composição as imagens de três personagens, sendo cada um deles construídos pela interação de elementos oriundos da história de Shrek e do futebol, especificamente, da seleção brasileira e sua derrota na copa de 2010.

Começamos nossa análise com a imagem de Shrek. Nessa imagem recuperamos traços do personagem principal dessa história e de Ricardo Teixeira, que na época era presidente da CBF (Confederação Brasileira de Futebol). A imagem, em conjunto com os modos verbal, sonoro e a imagem em movimento, possibilita a criação da metáfora RICARDO TEIXEIRA É SHREK. Em sua composição atuam dois domínios, Shrek e Ricardo Teixeira, o primeiro sendo seu domínio-fonte e o segundo seu domínio-alvo. Cada espaço é constituído de alguns elementos, esses podem ser recuperados ou através da própria charge, ou pelo conhecimento de mundo. Apresentamos abaixo esses espaços com seus respectivos elementos:

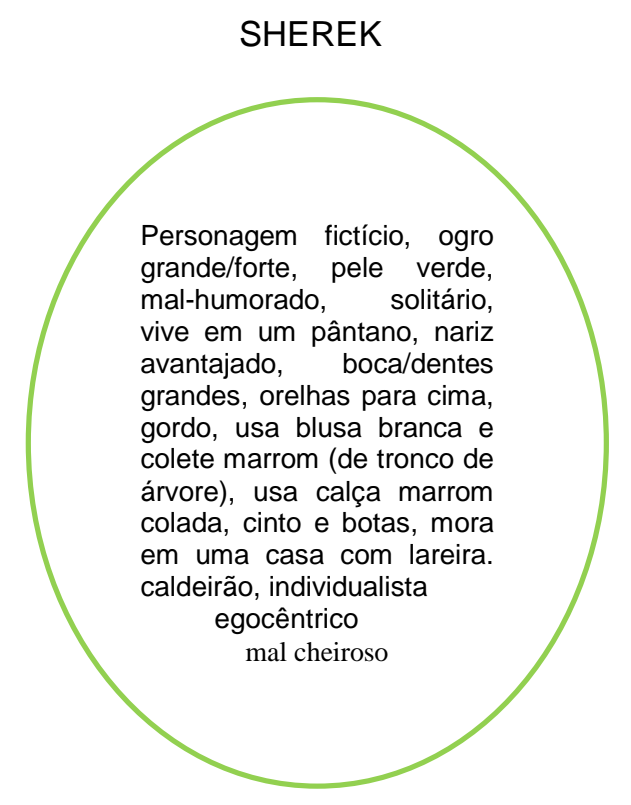

RICARDO TEIXEIRA

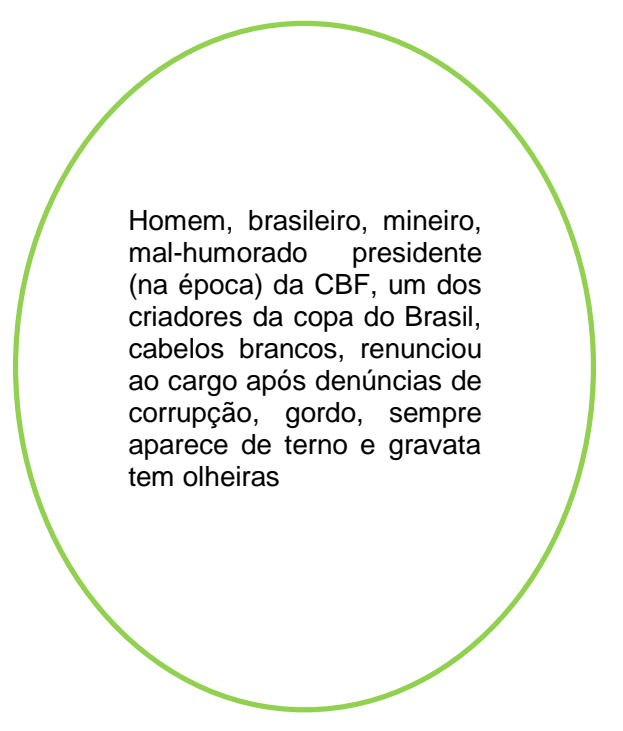

Com o mapeamento parcial entre os domínios há a criação de um novo espaço, nesse as identidades de Shrek e Ricardo Teixeira são fundidas, fazendo com que este adquira algumas características daquele. No novo espaço há uma nova estrutura, um novo frame, com relações inexistentes nos espaços de inputs.

RICARDO TEIXEIRA É SHEREK 
Além dos domínios fonte e alvo e do espaço mescla, essa rede é composta também pelo espaço genérico, com o que há de comum nos espaços de inputs. Nessa rede de integração, o espaço genérico é composto pelos elementos "mal-humor" e "sobrepeso", porque Shrek e Ricardo Teixeira possuem um gênio difícil e estão acima do peso.

Retomando a análise dos domínios fonte e alvo, afirmamos que, como o mapeamento entre esses espaços é parcial, havendo o mapeamento no interior de cada domínio antes do mapeamento entre os domínios, a relação entre os seus elementos é metonímica. Colocado isso, passamos, com base nos estudos de Jakobson (2003) e Paiva (2010, 2011, 2012), a analisar cada domínio através das propriedades de contiguidade, recursividade e fractalizada.

A propriedade de contiguidade atua na sua formação, tornando próximos os elementos que o constitui. Por isso, são contíguos todos os elementos desses espaços. No espaço Shrek "lareira" e "ogro" estão próximos, pois esse ogro vive em uma casa com lareira. Da mesma forma, no espaço Ricardo Teixeira os elementos "cabelo branco" e "CBF" são contíguos pelo fato de, na época, Ricardo ser o presidente da CBF e possuir cabelos brancos. A propriedade recursiva faz com que seja possível o caminho da PARTE ao TODO, como também o inverso, ou seja, ativar o TODO por meio de sua PARTE. Posto isso, no espaço Shrek podemos através da PARTE "pele verde" ativar TODO esse modelo, como também a partir do TODO "Shrek" ativar essa PARTE. Ocorrendo o mesmo com o espaço Ricardo Teixeira, com a PARTE "presidente da CBF" (na época) tornando possível o acesso ao TODO, e esse TODO ativando também essa PARTE. Por outro lado, há a metaforização, proposta por Paiva (2010, 2011, 2012), que são as PARTES de cada um desses espaços projetadas a um novo domínio, construindo a metáfora RICARDO TEIXEIRA É SHREK.

$\mathrm{Na}$ propriedade fractalizada, a metonímia é vista como hiperlink que possibilita a ativação total da cena. Assim, por exemplo, a voz de Shrek ou sua roupa, conduz à história de Shrek como um todo. Da mesma forma, a imagem, como o símbolo da CBF, em conjunto com a palavra confederação, permitem ativar TODO o espaço Ricardo Teixeira. Por outro lado, devido à característica de autossimilaridade, não haverá mudança de sentido, ou seja, podemos trabalhar com uma de suas PARTES ou com TODO o espaço que o sentido não muda, permanece 0 mesmo. Por isso, não importa se é ativado nesse contexto as PARTES "pele verde" ou "presidente da CBF" ou TODO o espaço "Shrek", ou "Ricardo Teixeira", porque estaremos trabalhando com a mesma coisa, apenas em escalas diferentes.

$A$ análise apresentada mostrou que a metáfora RICARDO TEIXEIRA É SHREK é construída por dois domínios, fonte e alvo, um espaço genérico e um espaço mescla. Assumimos que há relações metonímicas entre os elementos de cada espaços de inputs, pois há ativação, destacamento e mapeamento em cada espaço antes do mapeamento parcial de seus elementos ao espaço mescla, fenômeno considerado por Radden e Kövecses (1999) como metonímico. Assim, acreditamos que essa metáfora é motivada por um conjunto de metonímias que são produzidas pela interação dos elementos de cada espaço. Dessa forma, no espaço Shrek, existem as relações metonímicas PARTE pelo TODO (mal-humorado por Shrek, por exemplo), LUGAR por PERSONAGEM (pântano por Shrek), VESTUÁRIO por PERSONAGEM (blusa branca e colete marrom por Shrek) e OBJETO por PERSONAGEM (caldeirão por Shrek). No espaço Ricardo Teixeira, as relações metonímicas são: PARTE pelo TODO (cabelo branco por Ricardo Teixeira, por exemplo) VESTUÁRIO por PESSOA (gravata por Ricardo Teixeira) e CARGO por PESSOA (presidente da CBF na época por Ricardo Teixeira).

Retomando a leitura da charge, examinamos a metáfora DUNGA É O BURRO FALANTE. Essa possui os espaços mentais Burro Falante e Dunga, sendo esses seus domínios fonte e alvo, respectivamente. A charge em análise oferece alguns dos elementos que os constituem, enquanto que os 
outros são ativados a partir do conhecimento de mundo. A seguir expomos cada espaço e os elementos presentes em sua construção:
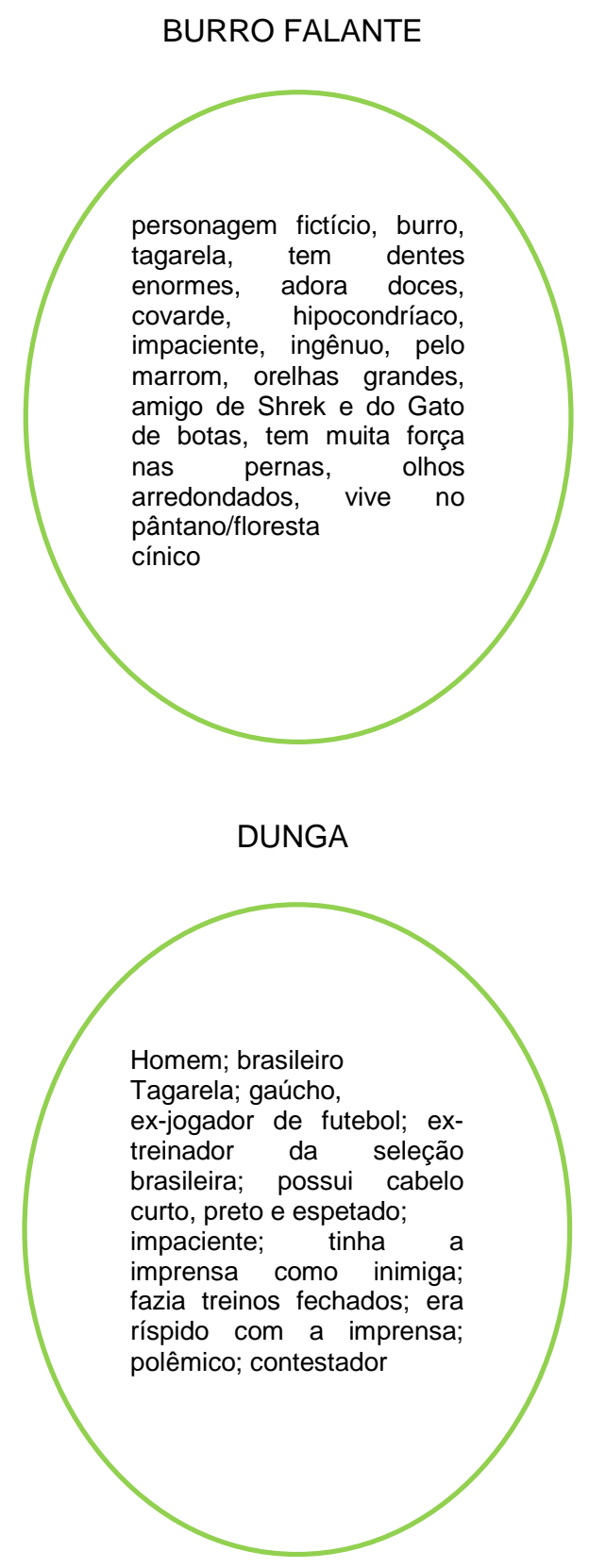

Relacionando parcialmente esses dois espaços mentais, cria-se a metáfora DUNGA É O BURRO FALANTE. Nesse novo espaço, a mescla, há a sobreposição das identidades de Dunga e o Burro Falante, fazendo com que aquele adquira algumas características deste:

\section{DUNGA É O BURRO FALANTE}

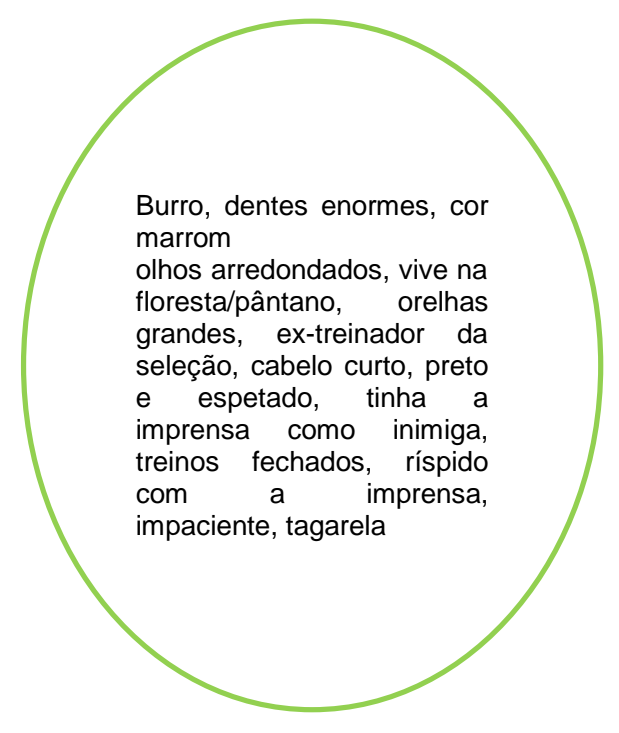

No espaço genérico da metáfora em análise encontram-se os elementos "impaciente" e "tagarela", pois ambos são impacientes e falam demais, no caso de Dunga esses elementos aplicam-se à sua relação com a imprensa durante a copa de 2010.

Como estamos argumentando no desenrolar desta pesquisa, acreditamos que as relações ocorridas entre os elementos de cada domínio são metonímicas. Diante disso, passamos a analisar esses espaços a partir das propriedades contígua, recursiva e fractalizada.

A primeira propriedade, a contiguidade, torna possível, no espaço Dunga, a proximidade dos elementos que o constitui, como "ex-treinador da seleção brasileira" e "inimigo da imprensa", pois os atritos de Dunga com a imprensa marcaram seu comando à frente da seleção em 2010. O mesmo pode ser visto no espaço burro falante, tornando próximos os elementos "tagarelo" e "cômico", porque essas são duas das características mais marcantes desse personagem. A propriedade recursiva proporciona traçar não apenas o caminho da PARTE ao TODO, mas também o inverso. Por isso, no espaço burro falante a PARTE "tagarela" permite ativar o TODO e através desse ativamos a PARTE "tagarela". De forma semelhante, no espaço Dunga, a PARTE "ex-treinador da seleção" ativa o TODO "Dunga", e esse TODO ativa essa PARTE. Por outro lado, como afirma Paiva $(2010,2011,2012)$, pode 
ocorrer a metaforização, onde as PARTES desses espaços são projetadas a um novo espaço, proporcionando a criação da metáfora. Fato que pode ser observado na análise em desenvolvimento, com PARTES de burro falante e Dunga sendo projetadas a um novo espaço, produzindo a metáfora DUNGA É O BURRO FALANTE.

A propriedade fractalizada fazendo com que os modos sonoro, imagético, verbal e a imagem em movimento funcionem como hiperlinks do espaço burro falante, possibilitando ativar a história de Shrek. Da mesma forma, o imagético, o verbal e o sonoro são hiperlinks do espaço Dunga, pois é a partir desses modos que recuperamos 0 contexto futebolístico da copa de 2010. Essa propriedade, devido sua característica autossimilar, faz com que, independente do modelo ser abordado como um TODO, ou uma de suas PARTES, não ocorre a alteração de sentido. Assim, podemos tomar TODO espaço "Dunga" ou "burro falante", ou uma de suas PARTES, "gaúcho" ou "amigo de Shrek", que o sentido desses espaços não se altera, o que ocorre é apenas uma mudança de escala.

A análise da metáfora DUNGA É O BURRO FALANTE demonstrou que sua construção é resultado de um grupo de metonímias produzidas pelas relações entre os elementos constituintes de cada domínio. As metonímias que atuam na produção dessa metáfora são: no espaço burro falante, a PARTE pelo TODO (amigo de Shrek por burro falante, por exemplo) e LUGAR por PERSONAGEM (pântano por burro falante), e, no espaço Dunga, as metonímias PARTE pelo TODO (inimigo da imprensa por Dunga, por exemplo), SOTAQUE por PESSOA (Tchê por Dunga) e PROFISSÃO por PESSOA (extécnico da seleção brasileira por Dunga). É através da compactação dessas metonímias que a metáfora em análise é criada.

Finalizamos com a descrição da metáfora MARADONA É O GATO DE BOTAS. Essa metáfora é constituída por dois domínios, Gato de Botas e Maradona. Cada domínio possui um conjunto de elementos, sendo esses oriundos ou da própria charge, ou do nosso conhecimento de mundo:
GATO DE BOTAS
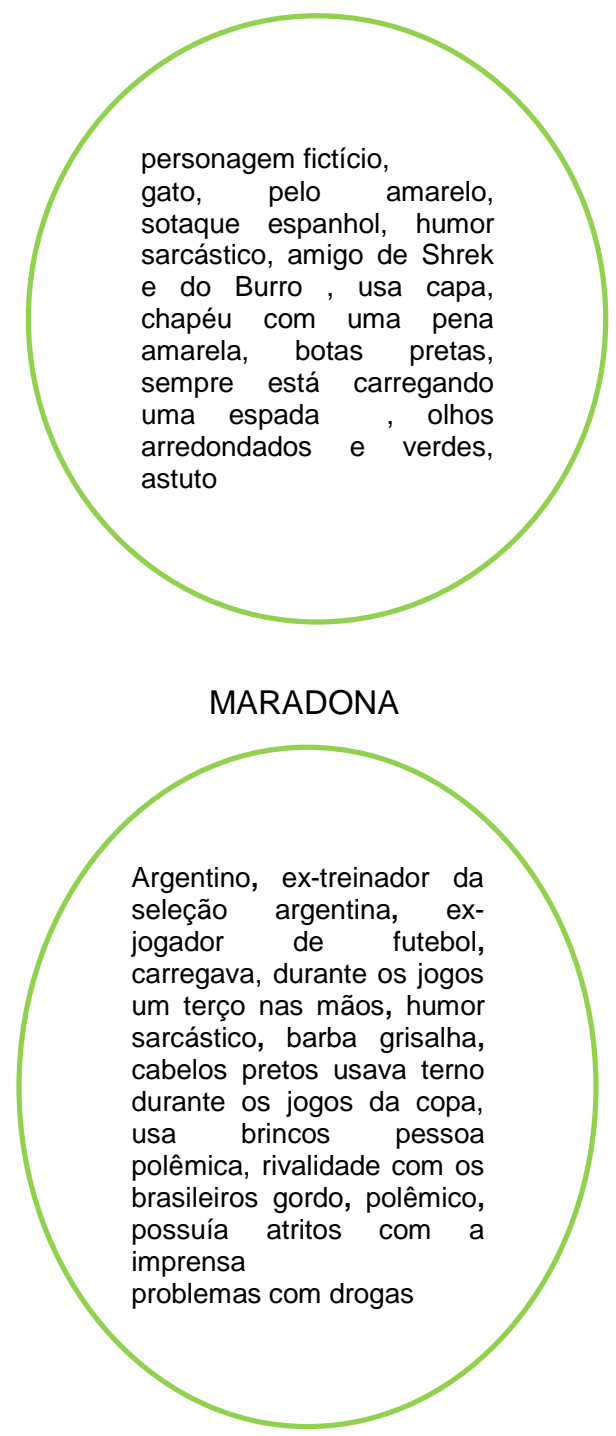

Ao relacionar parcialmente esses dois espaços, construímos o espaço mescla. Nesse espaço há a sobreposição da identidade de Maradona e do Gato de Botas:

\section{MARADONA É O GATO DE BOTAS}

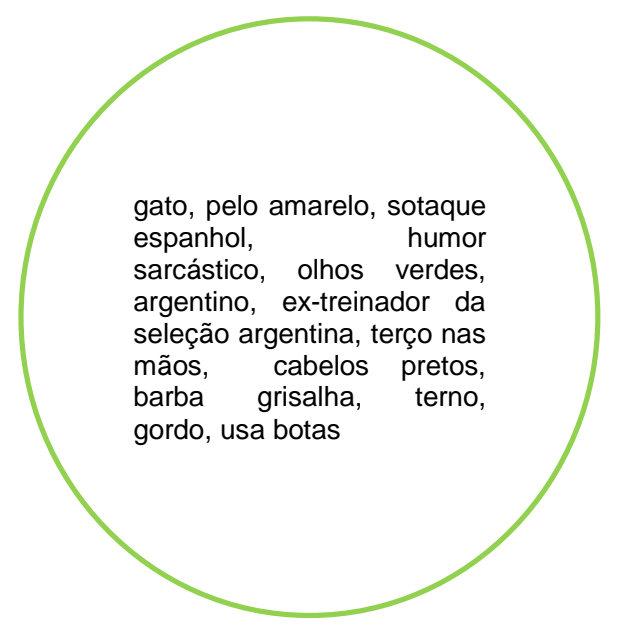


Além desses três espaços, há o espaço genérico com o que há de comum nos dois domínios. No espaço genérico Maradona e o Gato de Botas possuem em comum o "humor sarcástico" e o "sotaque espanhol".

Como ocorreu nas análises anteriores, continuamos considerando a existência de relações metonímicas entre os elementos que compõem os domínios dessa metáfora, passando a analisar cada um desses espaços a partir das propriedades de contiguidade, recursividade e fractalidade. Em sua formação se faz presente a propriedade contígua, tornando próximos os elementos "gato" e "capa", no espaço Gato de Botas, já que essa é uma peça indispensável para esse personagem; e "ex-treinador da seleção argentina" e "terço nas mãos", no espaço Maradona, pois esse objeto sempre estava presente nas mãos de Maradona durante os jogos de sua seleção.

A propriedade recursiva que permite o caminho do TODO a sua PARTE, como também o inverso, da PARTE ao seu TODO. Com essa propriedade a PARTE "ex-jogador de futebol" faz ativar o TODO "Maradona", como também o TODO essa PARTE. Da mesma forma, o TODO "Gato de Botas" permite ativar a PARTE "chapéu com pena amarela" e essa PARTE o TODO. Essa propriedade também conduz à metaforização, com as PARTES de cada um desses espaços sendo projetadas a um novo espaço, criando a metáfora em questão.

A propriedade fractalizada fazendo com que o verbal, o sonoro, o imagético e a imagem em movimento atuem como hiperlinks na ativação da história de Shrek, no espaço Gato de Botas; e no espaço Maradona os modos imagético, sonoro e verbal são hiperlinks na ativação do contexto futebolístico de 2010 como um todo. Devido à característica autossimilar, no processo metonímico, a mesma coisa é vista em escala diferente, ou seja, nos espaços Gato de Botas e Maradona podemos trabalhar com uma de suas PARTES ou com o espaço como um TODO que não haverá alteração de sentido. Assim, as PARTES pelo amarelo e argentino ou o TODO Gato de Botas e Maradona, nesse contexto, possuem o mesmo significado.

$\mathrm{Na}$ análise em desenvolvimento verificamos que a metáfora MARADONA É O GATO DE BOTAS é motivada por um conjunto complexo de relações metonímicas encontradas em cada um de seus domínios, sendo essas: no espaço Gato de Botas, PARTE pelo TODO (pelo amarelo por Gato de Botas, por exemplo), VESTUÁRIO por PERSONAGEM (capa/chapéu com pena amarela/botas por Gato de Botas), SOTAQUE ESPANHOL por PERSONAGEM (sotaque espanhol por Gato de Botas) e OBJETO por PERSONAGEM (espada/botas por Gato de Botas); no espaço Maradona, PARTE pelo TODO (argentino por Maradona, por exemplo), PROFISSÃO por PESSOA (ex-jogador de futebol/ ex-técnico da seleção argentina por Maradona), OBJETO por PESSOA (terço nas mãos durante os jogos por Maradona), SOTAQUE por PESSOA (sotaque espanhol por Maradona) e VESTUÁRIO por PESSOA (terno durante os jogos por Maradona).

\section{Conclusão}

No decorrer da visualização da charge "O ogro e o burro" foi possível verificar a utilização de três metáforas em sua construção: RICARDO TEIXEIRA É SHREK, DUNGA É O BURRO FALANTE $\mathrm{e}$ MARADONA É O GATO DE BOTAS. Com o auxílio da Teoria da Integração Conceitual, verificamos que essas metáforas foram motivadas por um grupo de metonímias presentes tanto em seu domínio-fonte quanto em seu domínio-alvo. Essa afirmação pode ser feita com base no conceito de metonímia por nós adotado, conceito proposto por Radden e Kövecses (1999), já que a metonímia passa a ser vista como entidade conceitual, veículo, que promove acesso mental a outra entidade, alvo, dentro de um mesmo domínio. Assim, por exemplo, na metáfora MARADONA É O GATO DE BOTAS, no domíniofonte GATO DE BOTAS, o elemento sotaque espanhol, neste contexto, nos permite ativar todo o domínio GATO DE BOTAS, produzindo a relação metonímica SOTAQUE ESPANHOL POR 
PERSONAGEM, relação presente na motivação dessa metáfora.

Além disso, foi possível promover um estudo mais aprofundado do processo metonímico por meio das propriedades contíguas, recursiva e fractalizada, que se fazem presentes na criação desses processos que motivaram as metáforas analisadas. Demonstramos que a propriedade contígua está presente na criação desses modelos, colocando os elementos presentes em sua constituição próximos. A recursividade faz com que no modelo metonímico o TODO seja ativado pela sua PARTE e essa pelo TODO, fato demonstrado no decorrer de nossa análise em cada domínio das metáforas apresentadas. Por último, a propriedade fractalizada que torna possível que cada um dos elementos apresentados pela charge funcionem com hiperlinks na ativação dos modelos metonímicos e, consequentemente, das metáforas por eles motivadas.

Nossa análise também nos permitiu observar um tipo de interação metafórica/metonímica diferente da proposta pelos autores precursores do estudo desse processo. Ou seja, Goossens (2003) e Barcelona (2003) promovem um estudo interativo que privilegia apenas a interação metonímica da metáfora presente em apenas um dos domínios dessa metáfora, fato observado nas metafonímias propostas por Goossens (2003) e na interação desenvolvida por Barcelona (2003). Por outro lado, Radden (2003) desenvolve a proposta do continuum, na qual o sentido passaria do literal para o metonímico, culminando no metafórico. Nossa análise apresentou uma perspectiva diferente, na qual demonstrou a possibilidade da motivação está presente tanto no domínio-fonte quanto no domínio-alvo da metáfora construída, tornando possível verificarmos um tipo de interação diferente das propostas por esses autores.

\section{Referências}

BARCELONA, Antonio. On the plausibility of claiming a metonymic motivation for conceptual metaphor. In: BARCELONA, Antonio. (Ed.). Metaphor and metonymy at the crossroads: a cogntive perspective. Berlin: Mouton de Gruyter, 2003b. p.31-58

FAUCONNIER, Gilles; TURNER, Mark. Metonymy and Conceptual Integration. In: PANTHER, Klaus-Uwe.; RADDEN, Günter. (Ed.). Metonymy in Language and Thought. Amsterdam: Benjamins, 1999. p. 77-90.

FAUCONNIER, Gilles; TURNER, Mark. The way we thing: conceptual blending and the mind's hidden complexities. New York: Basic Books, 2002.

GOOSSENS, Louis. Metaphtonymy: the interaction of metaphor and metonymy in expressions for linguisitc action. In: DIRVEN, René; PÖRINGS, Ralf. (Eds). Metaphor and metonymy in comparison and contrast. Berlin, New York: Mouton de Gruyter, 2003. p. 349377

JAKOBSON, Roman. The metaphoric and metonymic poles. In: DIRVEN, René; PÖRINGS, Ralf. (Eds). Metaphor and metonymy in comparison and contrast. Berlin, New York: Mouton de Gruyter, 2003. p. 41-47.

LAKOFF, George; JOHNSON, Mark. Metaphors we live by. Chicago: The University of Chicago Press, 1980.

LAKOFF, George. Women, fire and dangerous things. Chicago: University of Chicago Press, 1987.

PAIVA, Vera Lúcia Menezes de Oliveira. A Metonímia como processo fractal multimodal. Veredas, v. 01, n. atemática, p. 07-19, 2010. Disponível em: <www.ufjf.br/revistaveredas/files/2010/08/AR TIGO-1.pdf>. Acesso em: 10 set. 2010.

PAIVA, Vera Lúcia Menezes de Oliveira; NASCIMENTO, Milton. Processamento metafórico e metonímico na produção de texto/sentido: um exemplo de compressão fractal. As bordas da linguagem. Uberlândia: EDUFU, 2011. p.351-373

PAIVA, Vera Lúcia Menezes de Oliveira. O processamento metonímico/metafórico à luz da teoria do caos/complexidade. Revista Portuguesa de Humanidades-Estudos Linguísticos, Braga, v.15, n.1, p.51-66, 2012.

RADDEN, Günter; KÖVECSES, Zóltan. Towards a theory of metonymy. In: PANTHER, KlausUwe; RADDEN, Günter. (Eds). Metonymy in 
Language and Thought. Amsterdam: Benjamins, 1999. p. 17-59

RADDEN, Günter. How metonymic are metaphors? In: DIRVEN, René; PÖRINGS, Ralf. (Eds). Metaphor and metonymy in comparison and contrast. Berlin, New York: Mouton de Gruyter, 2003. p. 407-434.

RUIZ DE MENDONZA, Francisco Jose; PÉREZ, Lorena. Cognitive operations in pragmatic implication. In: PANTHER, Klaus-Uwe; THORNBURG, Linda. (Eds). Metonymy and pragmatic inferencing. Amsterdam: Benjamins, 2003. p. 23- 51

TAYLOR, John. Category extension by metonymy and metaphor. In: DIRVEN, René; PÖRING, Ralf. (eds.). Metaphor and metonymy in comparison and contrast. Berlin: New York: Mouton de Gruyter, 2003, p. 323-347. 